\title{
miR-214 targets the PTEN-mediated PI3K/Akt signaling pathway and regulates cell proliferation and apoptosis in ovarian cancer
}

\author{
JING LIU, WEIYAN CHEN, HAIYAN ZHANG, TING LIU and LIN ZHAO \\ Department of Gynecology, Linyi Tumor Hospital, Linyi, Shandong 276002, P.R. China
}

Received October 20, 2015; Accepted March 3, 2017

DOI: $10.3892 / 01.2017 .6953$

\begin{abstract}
The present study aimed to investigate the potential role of microRNA (miR)-214 in targeting the phosphatase and tensin homolog (PTEN)-mediated phosphoinositide 3-kinase (PI3K)/Akt signaling pathway in ovarian cancer (OC). The target gene of miR-214 was determined by luciferase reporter gene assay and was indicated to be PTEN. Human SK-OV-3 cells were transfected with a miR-214 inhibitor and a miR-214 mimic, and reverse transcription-quantitative polymerase chain reaction (RT-qPCR) was used to detect relative expression of miR-214. The MTT assay was performed to detect cell viability following transfection. Cell cycle and apoptosis were assessed by staining with propidium iodide (PI) and double staining with Annexin V/PI, respectively. The expression levels of PTEN and PI3K/Akt signaling pathway-associated proteins were detected by western blot analysis. The expression of miR-214 in tumor tissues and normal tissues was detected by RT-qPCR, and PTEN expression was detected by immunohistochemistry. SK-OV-3 cells transfected with a miR-214 inhibitor showed significantly inhibited cell viability and proliferation, and markedly increased apoptotic rate. SK-OV-3 cells transfected with miR-214 mimic showed significantly increased viability and proliferation, and markedly decreased apoptotic rate. The cells transfected with a miR-214 inhibitor exhibited significantly upregulated PTEN expression and significantly downregulated phosphatidylinositol (3,4,5)-trisphosphate (PIP3), phosphorylated (p)-Akt and $\mathrm{p}$-glycogen synthase kinase (GSK)- $3 \beta$ expression. The cells transfected with miR-214 mimic exhibited significantly downregulated PTEN expression and significantly upregulated PIP3, p-Akt and p-GSK-3 $\beta$ expressions. The OC tissues exhibited an increased expression of miR-214 and a reduced positive rate of PTEN expression compared with adjacent
\end{abstract}

Correspondence to: Dr Weiyan Chen, Department of Gynecology, Linyi Tumor Hospital, 6 Lingyuan East Road, Lanshan, Linyi, Shandong 276002, P.R. China

E-mail: chenweiyan1020@yeah.net

Key words: ovarian cancer, microRNA-214, phosphatase and tensin homolog, phosphoinositide 3-kinase/Akt signaling pathway, SK-OV-3, downregulation, proliferation, apoptosis normal tissues. miR-214 may activate the PI3K/Akt signaling pathway by downregulating the targeted PTEN, which may promote OC cell proliferation and inhibit apoptosis.

\section{Introduction}

As the fifth leading cause of cancer-associated mortalities resulting from gynecological malignancies, ovarian cancer (OC) presented with the highest incidence rates in Europe and North America, and lowest in Africa and Asia in 2008. Additionally, an estimated 22,240 new cases and 14,030 mortalities were reported in the United States and $\sim 4,500$ mortalities per year in the UK $(1,2)$. Although China still has the lowest rates and improved overall survival among patients with OC, increasing incidence rates and decreasing age of diagnosis was noted in patients with OC in a population-based registry in Taiwan and Hong Kong (3-5). In addition, patients suffering from $\mathrm{OC}$ are usually diagnosed at advanced stages, since early diagnosis is difficult due to the subtle and nonspecific initial symptoms; thus, significant efforts are directed at understanding the molecular mechanism and developing targeted therapy for OC (6). Deciphering of the signaling pathways brings about novel advances in the understanding of the pathogenic mechanism of ovarian carcinogenesis, and growing evidence has demonstrated that microRNAs (miRs) are differentially expressed in OC and may target molecular pathways involved in OC pathogenesis $(6,7)$.

Accumulating evidence revealed significant roles of miRs in various human cancers by modulating several biological and pathological processes, including differentiation, growth, proliferation and apoptosis in cells, as well as angiogenesis, invasion and metastasis in tumors (7-9). Putative tumor suppressor miR-214 regulates invasion and metastasis in hepatocellular carcinoma (HCC) and is able to directly or indirectly target CTNNB1 to modulate the $\beta$-catenin signaling pathway in HCC $(9,10)$. The role of miR-214 in driving melanoma metastasis has been demonstrated, and miR-214 may contribute to melanoma tumor progression $(11,12)$. miR-214 has been reported to function as an onco-miR in osteosarcoma, and promotes the proliferation and invasion of osteosarcoma cells by directly suppressing leucine zipper putative tumor suppressor 1 (13). Notably, down-regulated miR-214 expression has been found in human cervical cancer; upregulated miR-214 expression in HeLa cancer cells was found to significantly reduce cell growth (14). It has been suggested that miR-214 
serves a critical role in $\mathrm{OC}$ stem cells via regulation of the p53-Nanog axis (14). Previous studies presented evidence that miR-214 is frequently upregulated in OC tissues compared with normal ovarian tissues, and miR-214 induces cell survival and cisplatin resistance primarily through targeting the phosphatase and tensin homolog (PTEN)/Akt signaling pathway, leading to downregulated PTEN protein and activation of the Akt signaling pathway $(15,16)$. Studies have suggested that the phosphoinositide 3-kinase (PI3K)/Akt/mechanistic target of rapamycin (mTOR) pathway is frequently activated in OC and is a potential predictor of distinct invasive and migratory capacities in human OC cell lines, and the PTEN/PI3K/Akt/mTOR axis receives more attention in treatment of various types of cancer (17-19). Therefore, the present study aimed to evaluate the potential role of miR-214 in regulating the PTEN-mediated PI3K/Akt signaling pathway and to highlight the mechanisms of miR-214 in OC progression.

\section{Materials and methods}

Cell culture. The SK-OV-3 (human ovarian cancer) cell line was provided by the Cell Bank of the Chinese Academy of Sciences (Shanghai, China). SK-OV-3 cells were cultured in RPMI-1640 medium (Gibco; Thermo Fisher Scientific, Inc., Waltham, MA, USA) containing $10 \%$ fetal bovine serum (FBS; Hyclone; GE Healthcare Life Sciences, Logan, UT, USA), and incubated in a $5 \% \mathrm{CO}_{2}$ incubator at $37^{\circ} \mathrm{C}$. Cell subcultures were performed when cells were grown to $90 \%$ confluence. The primary medium was subsequently discarded. The cells were washed twice with phosphate-buffered saline (PBS), digested with trypsin (Gibco; Thermo Fisher Scientific, Inc.) and treated with the RPMI-1640 medium containing 10\% FBS to form a single-cell suspension. Routine subculture was performed. The cells in logarithmic phase were collected for subsequent usage.

Luciferase reporter gene assay. DNA extraction was performed with the TIANamp Genomic DNA kit (Tiangen Biotech Co., Beijing, China) according to the manufacturer's protocol. In order to investigate whether binding sites predicted by miR-214 induced changes in luciferase activity, PTEN-mutation (PTEN-mut; 5'-TTA-TTTTACTAGTTT TCAATCATAATACCTGACAT-3') and wide-type PTEN (PTEN-wt; 5'-TTA-TTTTACTAGTTTTCAATCATAATA CCTGCTGT-3') both from Synbio Technologies (Jiangshu, China), were designed and inserted into a reporter plasmid, which was purchased from Miaolingbio, Inc. (Hubei, China). PTEN and the corresponding miR-214 binding target site were determined using a target prediction software (Target Scan) (http://www.targetscan.org). Entering the 'Target Scan' and selecting Human in the column called 'Select a species', miR-214 was input in the column called 'Enter a microRNA name (e.g., miR-9-5p)', and the target site combined with PTEN were found. The PTEN gene was digested by EcoRI and SmalII. The digestion conditions were as follows: Following recovery of purpose gene fragments using $30 \mu \mathrm{l} K p n \mathrm{I}, 2 \mu \mathrm{l}$ HindIII, $2 \mu \mathrm{l}$ buffer and $5 \mu \mathrm{l} \mathrm{ddH}_{2} \mathrm{O}$, respectively, the fragments were sealed using T4 DNA ligase. Subsequently the sealed fragments were incubated with Escherichia coli DH5a from Weidi Biotechnology Co., Ltd. (Shanghai, China) at $37^{\circ} \mathrm{C}$ overnight. Finally, luciferase reporter gene pGL3 vectors were constructed. Luciferase activity was determined with a Dual-Luciferase Reporter assay system (E1910; Promega Corporation, Madison, WI, USA). Following transfection at $37^{\circ} \mathrm{C}$ for $48 \mathrm{~h}$, the culture medium was removed. The cells were washed with PBS twice. Passive lysis buffer (100 $\mu$ l per well) was added, and the cells were gently agitated for $15 \mathrm{~min}$ at room temperature to obtain cell lysate. The program was set with a 2 -sec pre-read delay followed by a 10 -sec measurement period, and luciferase assay reagent II (LARII; $100 \mu \mathrm{l}$ ) and Stop \& $\mathrm{Glo}^{\circledR}$ reagent $(100 \mu \mathrm{l})$ were added to each sample. The prepared LARII and Stop \& Glo ${ }^{\circledR}$ reagent and luminous tubes or plates containing the cell lysate were placed into a bioluminescence detection system (Bio-Rad Laboratories, Inc., Hercules, CA, USA). The program was run, and data were saved at the end of reading.

Cell transfection. The cells were divided into four groups: Blank (cells untransfected with any miR-214 sequence), negative control (NC), miR-214 mimic and miR-214 inhibitor. The cells in the $\mathrm{NC}$ group were transfected with a vector containing the miR-214 NC sequence (5'CCUGACAAUUAGUAUUU-3'; Shanghai GenePharma Co.,Ltd., Shanghai, China) and the cells in the miR-214 mimic group were transfected with a miR-214 mimic (5'-ACAGGUAGCUGA ACACUGGGUU-3'; Synbio Technologies). The cells in the miR-214 inhibitor group were transfected with mirVana ${ }^{\mathrm{TM}}$ miRNA inhibitor (5'-UCACAG UGCUCAUCAUGAAUAA-3'; Shanghai Bioleaf, Shanghai, China). SK-OV-3 cells (200 $\mu 1 /$ well) in the logarithmic growth phase were seeded on a 6-well plate with antibiotic-free complete medium. SK-OV-3 cells were transfected with Lipofectamine 2000 (Invitrogen; Thermo Fisher Scientific, Inc.) when cell density reached $30-50 \%$, according to the manufacturer's instructions. The miR-214 NC vector, miR-214 mimic and a miR-214 inhibitor (100 pmol; final concentration, $50 \mathrm{nM}$ ) were respectively diluted in $250 \mu 1$ serum-free medium Opti-MEM (Gibco; Thermo Fisher Scientific, Inc.), gently mixed until even and incubated for $5 \mathrm{~min}$ at room temperature. Lipofectamine $2000(5 \mu \mathrm{l})$ was diluted in $250 \mu \mathrm{l}$ serum-free medium Opti-MEM (Gibco; Thermo Fisher Scientific, Inc.), gently mixed until even, and incubated for $5 \mathrm{~min}$ at room temperature. The diluted miR-214 $\mathrm{NC}$ vector, miR-214 mimic and miR-214 inhibitor were evenly mixed with the diluted Lipofectamine 2000, respectively. The mixture was added into the well containing cells following incubation for $20 \mathrm{~min}$ at room temperature and gently mixed until even. The transfected cells were placed in a $5 \% \mathrm{CO}_{2}$ incubator at $37^{\circ} \mathrm{C}$. The medium was replaced with complete medium after 6-8 $\mathrm{h}$ incubation at $37^{\circ} \mathrm{C}$, and the transfected cells were incubated at $37^{\circ} \mathrm{C}$ for $24-48 \mathrm{~h}$ for subsequent experiments.

MTT colorimetric assay. The cells (80\% confluence) were washed twice with PBS and digested with $0.25 \%$ trypsin (Gibco; Thermo Fisher Scientific, Inc.) to form a single-cell suspension. The cells were counted using Moxi $\mathrm{Z}$ mini automated cell counter (Bio Excellence International Tech Co., Ltd., Beijing, China), according to the manufacturer's instructions and were inoculated in a 96 -well plate ( $200 \mu \mathrm{l}$ per well, 6 repeated wells) at a density of $3 \times 10^{3}$ to $6 \times 10^{3}$. Following culture at $37^{\circ} \mathrm{C}$ for $48 \mathrm{~h}, 5 \mathrm{mg} / \mathrm{ml}$ MTT solution $(20 \mu \mathrm{l})$ was added to each 
well. After $4 \mathrm{~h}$ incubation at $37^{\circ} \mathrm{C}$, the culture medium was discarded. Dimethyl sulfoxide (150 $\mu \mathrm{l}$; Sigma-Aldrich; Merck KGaA, Darmstadt, Germany) was added to each well and gently agitated for $10 \mathrm{~min}$. Optical density (OD) values were determined at a wavelength of $490 \mathrm{~nm}$ with an enzyme-linked immunosorbent detector (De Tie Inc., Nanjing, China) at 12, 24 and $48 \mathrm{~h}$, respectively. Cell viability curves were plotted with time as the $\mathrm{x}$-axis and the OD value as the $\mathrm{y}$-axis.

Apoptosis detected by Annexin $V$ and PI staining. Following a 48 -h transfection at $37^{\circ} \mathrm{C}$, the cells were digested with the EDTA-free trypsin and collected in the flow tube for centrifugation at $157 \mathrm{x} \mathrm{g}$ at $4^{\circ} \mathrm{C}$ for $5 \mathrm{~min}$, and the supernatant was discarded. Cells were washed three times with PBS, and subsequently centrifuged at $157 \mathrm{x}$ g at $4^{\circ} \mathrm{C}$ for $5 \mathrm{~min}$ for removal of supernatant. According to the manufacturer's instructions, $150 \mu \mathrm{l}$ binding buffer and $5 \mu \mathrm{l}$ (per tube) Annexin V-FITC [Annexin V-fluorescein isothiocyanate (FITC) apoptosis detection kit; Sigma-Aldrich; Merck KGaA] was added to the cells and gently agitated. The cells were incubated in darkness for $15 \mathrm{~min}$ at room temperature, and an additional $100 \mu \mathrm{l}$ binding buffer and $5 \mu \mathrm{l}$ propidium iodide (PI) dye (Sigma-Aldrich; Merck KGaA) was added. The mixture was oscillated and mixed evenly. The proportion of cells undergoing apoptosis was analyzed by CytoFLEX flow cytometer (Beckman Coulter, Inc., Brea, CA, USA) and the results were analyzed using CytExpert 2.0 software (Beckman Coulter, Inc.).

PI staining for cell cycle analysis. Following a 48-h transfection at $37^{\circ} \mathrm{C}$, the cells were collected, washed with cold PBS for three times and centrifuged at $157 \mathrm{x}$ g at $4^{\circ} \mathrm{C}$ for $5 \mathrm{~min}$ to remove the supernatant. Cell concentration was adjusted to $\sim 1 \times 10^{5} / \mathrm{ml}$, and the cells were fixed with $1 \mathrm{ml} 75 \%$ ice-cold ethanol overnight at $4^{\circ} \mathrm{C}$. The cells were subsequently washed twice with PBS with supernatant discarded prior to staining and $100 \mu \mathrm{l}$ RNase A was then added in darkness. The cells were incubated in a $37^{\circ} \mathrm{C}$ water bath for $30 \mathrm{~min}$, stained with $400 \mu \mathrm{l}$ PI and mixed evenly. Subsequently, the samples were incubated in the dark at $4^{\circ} \mathrm{C}$ for $30 \mathrm{~min}$. Cell cycle was analyzed by detecting red fluorescence at excitation wavelength of $488 \mathrm{~nm}$ with the CytoFLEX flow cytometer (Beckman Coulter, Inc.).

Western blot analysis. After $48 \mathrm{~h}$ of transfection, the cells were collected, lysed by Tissue Total Protein Lysis Buffer Solution (Shanghai Yu Bo Biological Technology Co., Ltd., Shanghai, China) and centrifuged. The bicinchoninic acid kit (Thermo Fisher Scientific, Inc.) was used following the manufacturer's instructions to measure total protein concentration. The total protein $(20 \mu \mathrm{g})$ was run on a $12 \%$ SDS-PAGE and electro-transferred to polyvinylidene fluoride membranes. The membranes were blocked with skimmed milk at room temperature for $1 \mathrm{~h}$, incubated with monoclonal antibodies GAPDH (GTX101025, 1:500), PTEN (GTX101025, 1:500), PIP3 (GTX119163, 1:500), Akt (GTX128414, 1:500), phosphorylated (p)-Akt (GTX121937, 1:500), glycogen synthase kinase (GSK)-3 $\beta$ (GTX111192, 1:500) and p-GSK-3 $\beta$ (GTX132997, 1:500; all from Santa Cruz Biotechnology, Inc., Santa Cruz, CA, USA) overnight at $4^{\circ} \mathrm{C}$. The membrane was washed with PBS three times to remove primary antibodies and incubated with horseradish peroxidase-labeled goat anti-rabbit secondary antibody
(GTX77266, 1:500; Beyotime Institute of Biotechnology, Haimen, China) at room temperature for 1-2 h, washed with PBS three times, and an electro-chemiluminescence (ECL) color developing kit (Shanghai Yeasen Biotechnology Co., Ltd., Shanghai, China) for visualization of the bands, according the manufacturer's instructions. Images were captured using an in vivo imaging system (LAS-4000; GE Healthcare Life Sciences) and the relative molecular mass and net absorption of the target bands were analyzed by a gel image processing system. The data were normalized with the expression of $\beta$-actin. Using GAPDH as a reference, the relative expression of target proteins was analyzed using ImageJ version 2 x 2.1.4.7 software (National Institutes of Health, Bethesda, MD, USA).

Study subjects. The specimens were obtained from 124 patients with OC who underwent surgical treatment in Linyi Tumor Hospital (Linyi, China) between February 2013 and February 2015. All the specimens were confirmed by pathological diagnosis. All patients were females with childbearing history (the mean age, $48.17 \pm 10.32$ years; range, 34-73 years), who had received no preoperative chemotherapy. Surgical-pathological staging (20) of the patients are as follows: Stage I $(n=40)$; stage II $(n=36)$; stage III $(n=42)$; and stage IV $(n=6)$. Histological types and pathological grading (21) of the patients are as follows: Serous carcinoma $(n=74)$; mucinous carcinoma $(n=29)$; and endometrioid carcinoma $(n=21)$; and G1 (well-differentiated) $(n=47)$; G2 (moderately-differentiated) $(n=26)$; and G3 (poorly-differentiated) $(n=51)$. Lymph-node-metastasis statuses of the patients are as follows: Positive $(n=88)$ and negative $(n=36)$. The specimens collected from OC tissues and normal mucosa tissues $(5 \mathrm{~cm}$ away from the edge of carcinoma) were treated with liquid nitrogen and stored in a $-70^{\circ} \mathrm{C}$ freezer. Half of the specimens $(n=62)$ were used for the detection of miR-214, and the other half $(n=62)$ were fixed with $10 \%$ formalin at room temperature for $30 \mathrm{~min}$, paraffin-embedded and used for immunohistochemistry. The present study protocol was approved by the Ethics Committee of Linyi Tumor Hospital, and all patients signed informed consent.

Analysis of miR-214 expression in OC tissues and adjacent normal tissues by reverse transcription-quantitative polymerase chain reaction ( $R T-q P C R)$. Analysis of miR-214 expression in OC tissues and adjacent normal tissues was performed with RT-qPCR. The total RNA was extracted from frozen tissues (50 mg) with a miRNeasy Mini kit (Qiagen, Inc., Valencia, CA, USA) following the manufacturer's instructions. RNA sample $(5 \mu \mathrm{l})$ was diluted (20X) with RNase-free ultra-pure water (Beijing Solarbio Science \& Technology Co., Ltd., Beijing, China). The adsorptions of UV light at wavelengths 260 and $280 \mathrm{~nm}$ (OD260/OD280 ratio) were read from the ultraviolet spectrophotometer (Mettler Toledo Instruments, Shanghai, China) to determine purity and contamination of the RNA samples. Only high-purity RNA samples with an OD260/OD280 ratio of 1.7-2.1 were used for subsequent analysis. Complementary DNA (cDNA) was obtained by reverse transcription with a PCR amplification instrument. A total of $9.0 \mu \mathrm{l}$ diethyl pyrocarbonate (DEPC)-treated water, $0.6 \mu 1$ reverse primers $(20 \mathrm{pmol} / \mu \mathrm{l}), 0.1 \mu \mathrm{l}$ enzyme inhibitor $(40 \mathrm{U} / \mu \mathrm{l})$ and $5 \mu$ l RNA solution were added to a microcentrifuge tube 
$(0.5 \mathrm{ml}$, RNase-free). Following incubation in a water bath at $70^{\circ} \mathrm{C}$ for $5 \mathrm{~min}$ and in an ice bath for $5 \mathrm{~min}$, the mixture was incubated with $4.0 \mu 15 \mathrm{xAMV}$ reverse transcription buffer, $1.0 \mu \mathrm{l}$ dNTP Mixture (10 mol/l), $0.1 \mu 1$ RNA enzyme inhibitor $(40 \mathrm{U} / \mu \mathrm{l})$ and $0.2 \mu \mathrm{l}$ AMV Reverse Transcriptase $(5 \mathrm{U} / \mu \mathrm{l})$ at $42^{\circ} \mathrm{C}$ for $40 \mathrm{~min}$, followed by amplification using a PCR instrument. RT-qPCR experiment was performed using a ABI7500 quantitative PCR instrument (Applied Biosystems; Thermo Fisher Scientific, Inc.) with the following PCR conditions: Pre-denaturing $\left(95^{\circ} \mathrm{C}, 10 \mathrm{~min}\right)$; followed by 40 cycles of denaturing at $95^{\circ} \mathrm{C}$ for $10 \mathrm{sec}$ and annealing at $60^{\circ} \mathrm{C}$ for $20 \mathrm{sec}$; and extension at $72^{\circ} \mathrm{C}$ for $34 \mathrm{sec}$. Real-time detection was performed using SYBR-Green (Thermo Fisher Scientific, Inc.) with maximum absorption wavelength $497 \mathrm{~nm}$ and emission maximum wavelength $520 \mathrm{~nm}$ for fluorescence signals. The sequences of the primers used are as follows: miR-214 forward, 5'-CACCTTTCTCCCTTTCCCCTTACT CTCC-3' and reverse, 5'-TTTCATAGGCACCACTCACTT TAC-3'; U6 (internal control) forward, 5'-CTCGCTTCGGCA GCACA-3' and reverse, 5'-AACGCTTCACGAATTTGCGT-3'. The $2^{-\Delta \Delta C q}$ method (22) was used for normalization and was calculated as follows: $2^{-\Delta \Delta C q}=\Delta \mathrm{Cq}_{\text {experiment group }}-\Delta \mathrm{Cq}_{\text {control group. }}$ $\Delta \mathrm{Cq}=\mathrm{Cq}_{\mathrm{miRNA}}-\mathrm{Cq}_{\mathrm{U}}$, where $\mathrm{Cq}$ is the number of amplification cycles when the real-time fluorescence intensity of the reaction reaches the threshold values. Amplification was performed during a period of logarithmic growth. Each experiments were repeated 3 times.

Analysis of PTEN expression in OC and adjacent normal tissues by immunohistochemistry. The $10 \%$ formalin fixed and paraffin-embedded specimens $(n=62)$ were cut into 4 $\mu \mathrm{m}$-thick sections. The tissue slices were dried in an oven at $60^{\circ} \mathrm{C}$ for $1 \mathrm{~h}$, dewaxed with xylene, dehydrated in graded ethanol $\left(50,70,80\right.$ and 95\%) and incubated with $3 \% \mathrm{H}_{2} \mathrm{O}_{2}$ (Sigma-Aldrich; Merck KGaA) at $37^{\circ} \mathrm{C}$ for $30 \mathrm{~min}$, washed with PBS and placed in $0.01 \mathrm{M}$ citrate buffer, boiled at $95^{\circ} \mathrm{C}$ for $20 \mathrm{~min}$, cooled to room temperature and washed with PBS. The washed tissue sections were incubated at $37^{\circ} \mathrm{C}$ for 10 min in blocking medium containing normal goat serum (Wak-Chemie Medical GmbH, Steinbach, Germany), incubated with the primary antibody (cat. no. GTX101025; PTEN; 1:100; Santa Cruz Biotechnology, Inc.) overnight at $4^{\circ} \mathrm{C}$, rinsed with PBS, and additionally incubated with the horseradish peroxidase-labeled secondary antibody (GTX77266, 1:500, Beijing Biosynthesis Biotechnology Co., Ltd.) for $30 \mathrm{~min}$ at room temperature. The sections were visualized using 3,3'-diaminobenzidine tetrahydrochloride (Sigma-Aldrich; Merck KGaA) followed by staining with hematoxylin $(5 \mathrm{mg} / \mathrm{ml}$; Shanghai Bogoo Biotechnology. Co., Ltd., Shanghai, China) and mounting. A negative control was prepared by replacing the primary antibody with PBS, and normal mucosa tissues were used as a positive control. The expression of PTEN was mainly observed in the cell nucleus and partially in the cytoplasm, presenting with yellow or brownish-yellow granules. A total of five high-power fields ( $\mathrm{x} 400,100$ counted cells per field) using a CX31-LV320 OLYMPUS microscope (Chang Heng Rong technology Co., Ltd., Beijing, China) in each tissue section were randomly selected, and positive cells/all tumor cells $>10 \%$ was considered as positive (+) and positive cells $\leq 10 \%$ as negative (-). The results of immunohistochemistry
A

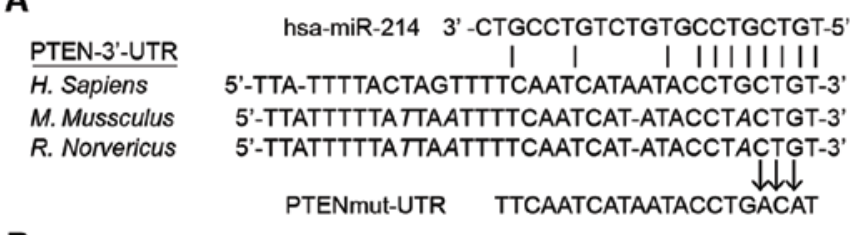

B

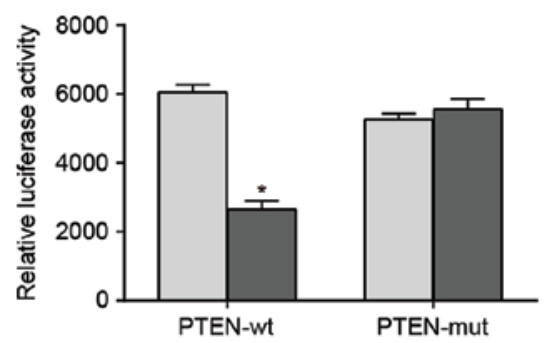

$\square$ Negative control

miR-214 mimics

Figure 1. Predicted binding site of miR-214 in the PTEN. (A) Binding of miR-214 to the 3'-UTR of PTEN mRNA; (B) Detection of reporter gene activity based on the dual luciferase reporter system. SK-OV-3 cells were co-transfected with miR-214 mimic, Wt-miR-214/PTEN and Mut-miR-214/PTEN; miR-214 was able to significantly inhibit the luciferase activity of Wt-miR-214/PTEN plasmid but had no significant effect on the luciferase activity of Mut-miR-214/PTEN plasmid; * $\mathrm{P}<0.05$ compared with the NC group. PTEN, phosphatase and tensin homolog; miR, microRNA; Mut, mutated; UTR, untranslated region; Wt, wild-type; NC, negative control.

were evaluated independently by two experienced observers using a double-blind approach.

Statistical analysis. Continuous variables are presented as the mean \pm standard deviation. The comparison between the two groups was performed using paired t-test, and the comparison among the groups was analyzed using one-way analysis of variance. Categorical variables are presented as frequencies and percentages, and comparisons were performed with $\chi^{2}$ test. SPSS 18.0 software (SPSS, Inc., Chicago, IL, USA) was used for statistical analysis. $\mathrm{P}<0.05$ was considered to indicate a statistically significant difference.

\section{Results}

Verification of miR-214 target gene. The sequences of miR-214 binding with 3'-UTR region of PTEN mRNA were illustrated in Fig. 1A. In order to demonstrate that the miR-214 seed region was able to interact with 3'UTR region of PTEN mRNA and leads to altered luciferase activity, the designed mutated sequence (PTEN 3'-UTR mRNA which lacks the putative miR-214 binding site) and the wild sequence were inserted into the reporter gene plasmid. SK-OV-3 cells were co-transfected with miR-214 mimic, wild recombinant plasmid (Wt-miR-214/PTEN) and mutated recombinant plasmid (Mut-miR-214/PTEN). The luciferase activity assay indicated that transfection with miR-214 mimic had no significant effect on the luciferase activity of the cells in the Mut-miR-214/PTEN plasmid group compared with cells in the negative control. By contrast, luciferase activity of the cells in the Wt-miR-214/PTEN plasmid group decreased by $\sim 62 \%$ compared with the negative control $(\mathrm{P}<0.05$; Fig. 1B).

miR-214 expression. RT-qPCR results indicated that the expression of miR-214 decreased significantly in the SK-OV-3 


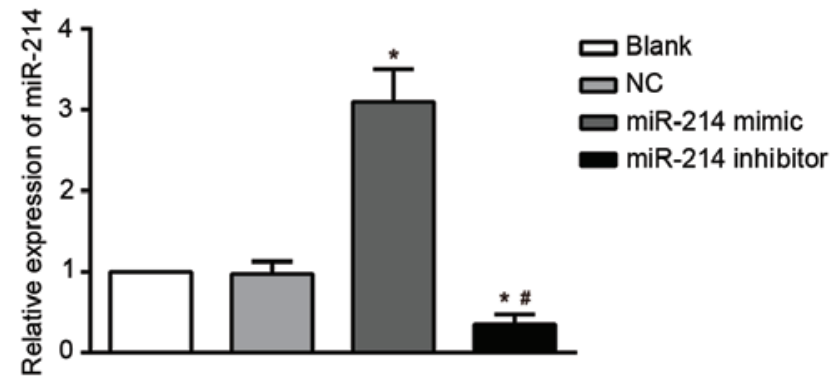

Figure 2. miR-214 expression in SK-OV-3 cells transfected with a miR-214 inhibitor and a miR-214 mimic after $48 \mathrm{~h}$ of transfection; ${ }^{*} \mathrm{P}<0.05$ compared with the blank and $\mathrm{NC}$ groups; ${ }^{*} \mathrm{P}<0.05$ compared with the miR-214 mimic group; NC, negative control; miR, microRNA; blank, cells untransfected with miR-214.

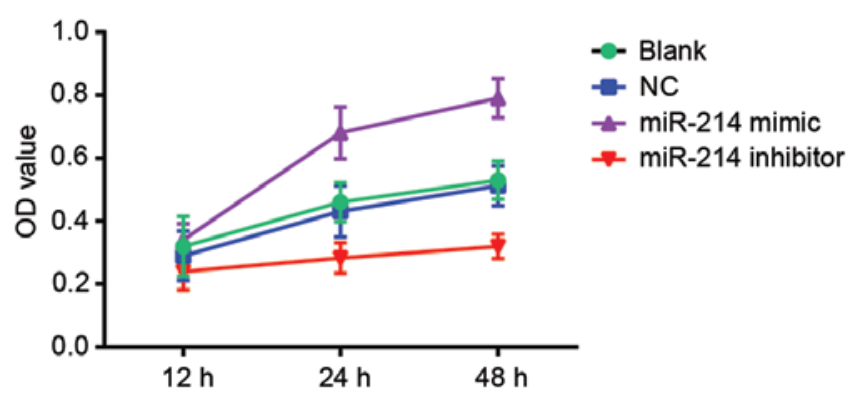

Figure 3. Viability curves of SK-OV-3 cells transfected with miR-214 mimic and treated with miR-214 inhibitor following $48 \mathrm{~h}$ of incubation by MTT assay. miR-214 mimic significantly promoted the viability of SK-OV-3 cells, and miR-214 inhibitor significantly inhibited the viability of SK-OV-3 cells. $\mathrm{NC}$, negative control; miR, microRNA; OD, optical density; blank, cells untransfected with miR-214.

cells transfected with a miR-214 inhibitor compared with the untransfected cells (blank) and NC groups. By contrast, there was a significant increase in miR-214 expression in the miR-214 mimic group compared with the blank (all $\mathrm{P}<0.05$ ). miR-214 expression was markedly lower in the miR-214 inhibitor group compared with the miR-214 mimic group $(\mathrm{P}<0.05)$. There were no significant differences in miR-214 expression between the blank and NC P>0.05; Fig. 2).

Effect of miR-214 expression on the viability of SK-OV-3 cells. MTT assay indicated that, cell viability was significantly inhibited in the miR-214 inhibitor group compared with the blank and the NC group $(\mathrm{P}<0.05)$. There were significant differences in OD values between the miR-214 inhibitor group and the blank group at the time points 24 and $48 \mathrm{~h}(\mathrm{P}<0.05)$. There were also significant differences between the miR-214 inhibitor group and $\mathrm{NC}$ group $(\mathrm{P}<0.05)$. Cell viability increased significantly in the miR-214 mimic group compared with the blank and the NC group. Significant differences in OD values were observed between the miR-214 mimic group and the blank and the NC group at the time points 24 and $48 \mathrm{~h}$ (both $\mathrm{P}<0.05)$. Significantly increased OD values were observed in the miR-214 mimic group compared with the miR-214 inhibitor group at the time points of 24 and $48 \mathrm{~h}(\mathrm{P}<0.05)$. The comparison of OD values between the blank and the NC group showed no significant difference at any time points (all $\mathrm{P}>0.05$ ). With the increase in time, there were significant differences
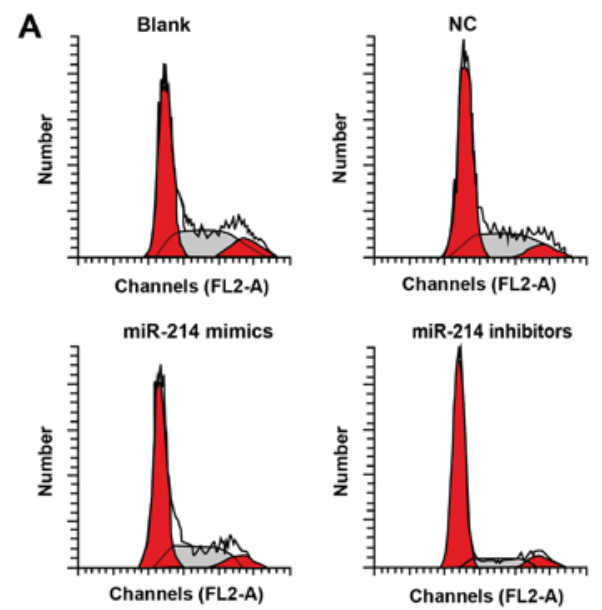

B

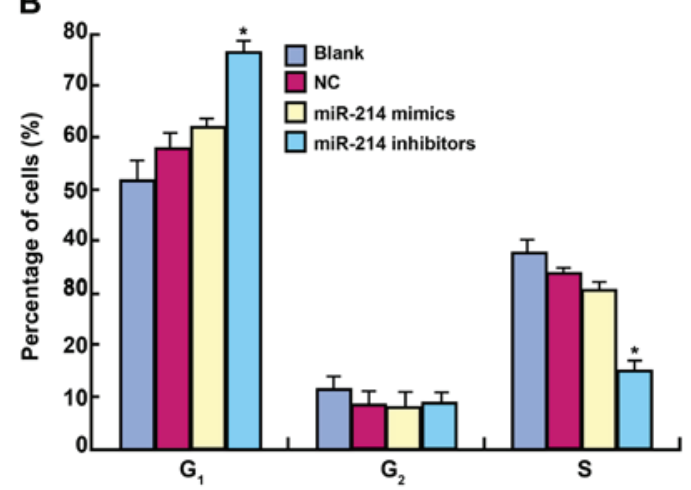

Figure 4. Cell cycle analysis of SK-OV-3 cells transfected with miR-214 mimic and treated with a miR-214 inhibitor by propidium iodide staining. After $48 \mathrm{~h}$ of transfection, the majority of cells treated with a miR-214 inhibitor were in G1. By contrast, the proportion of miR-214 inhibitor-treated cells in the S phase was significantly decreased, and the proliferation of SK-OV-3 cells was significantly inhibited compared with cells in the blank, the NC and the miR-214 mimic group. ${ }^{*} \mathrm{P}<0.05$ compared with the blank, $\mathrm{NC}$ and miR-214 mimic groups; NC, negative control; miR, microRNA; blank, cells untransfected with miR-214.

in OD among different groups [multivariate analysis of variance $(F)=24.544 ; \mathrm{P}<0.001]$. There were significant differences in OD values between the different time points $(\mathrm{F}=217.932$; $\mathrm{P}<0.001)$. Additionally, there was interaction between the measurement time and group $(\mathrm{F}=23.839 ; \mathrm{P}<0.001$; Fig. 3).

Cell cycle and apoptotic rate. PI staining results showed that the proportion of cells in $\mathrm{G} 1$ in the blank, NC, miR-214 mimic and miR-214 inhibitor groups were $56.39 \pm 3.82,57.62 \pm 3.34$, $60.34 \pm 2.38$ and $76.40 \pm 2.22 \%$, respectively (Fig. 4). The majority of cells treated with a miR-214 inhibitor were in G1. By contrast, the proportion of miR-214 inhibitor-treated cells in the $\mathrm{S}$ phase was decreased, and the proliferation of miR-214 inhibitor-treated cells was significantly inhibited compared with cells in the blank, the NC and the miR-214 mimic group. No significant difference in the proportion of cells in G1, G2 and $\mathrm{S}$ existed in the miR-214 mimic group, the blank group and the NC group (all $\mathrm{P}>0.05$ ).

Double staining with Annexin V and PI results indicated that $48 \mathrm{~h}$ following transfection, apoptotic rates in the blank, the NC, the miR-214 mimic group and the miR-214 inhibitor group were $11.4,10.9,4.9$ and $28.1 \%$, respectively. The apoptotic rate of SK-OV-3 cells in the miR-214 inhibitor group was 

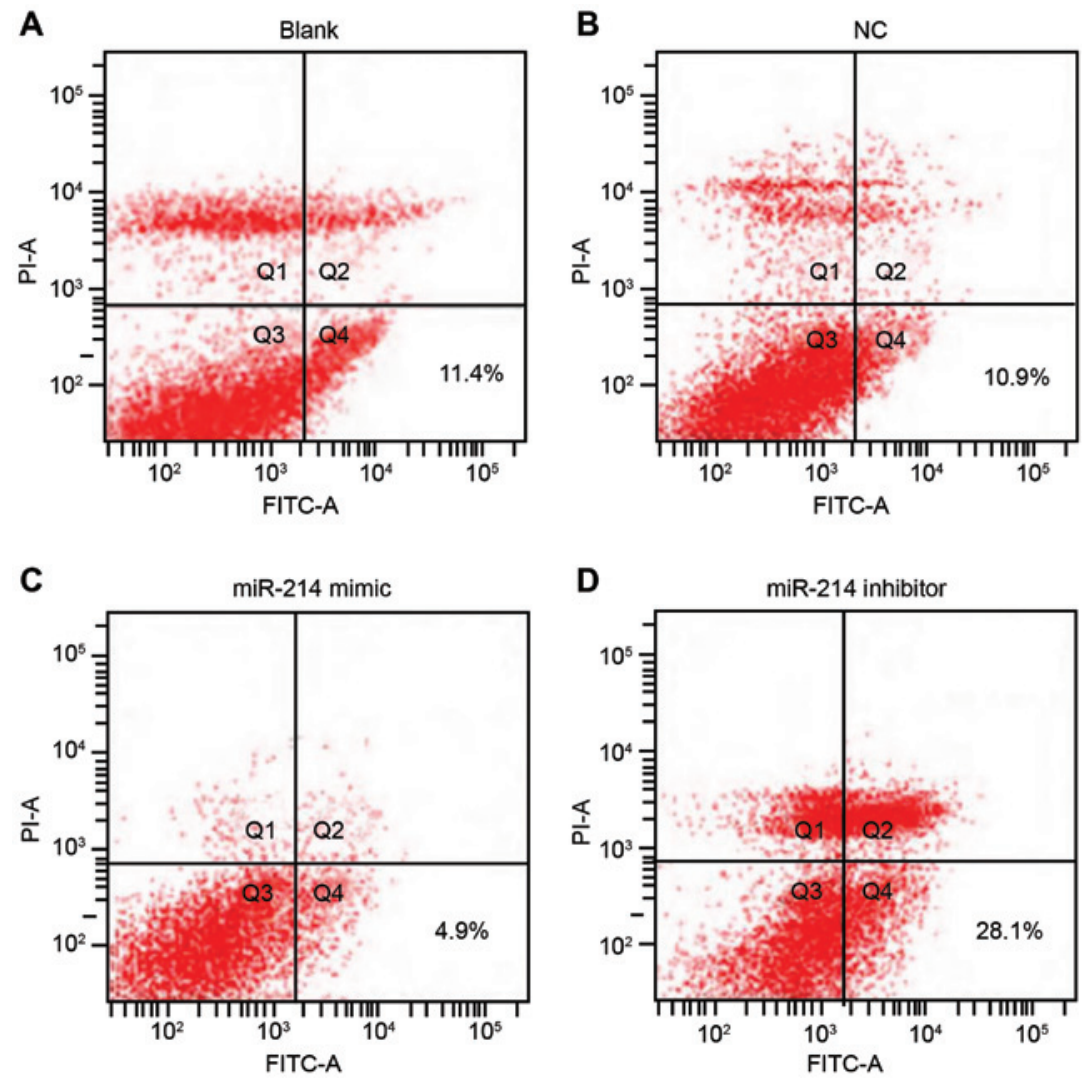

Figure 5. Analysis of apoptosis by double staining with Annexin V and PI. (A) Blank, (B) NC, (C) miR-214 mimic and (D) miR-214 inhibitor group. The cells were analyzed $48 \mathrm{~h}$ following transfection. NC, negative control; PI, propidium iodide; FITC, fluorescein isothiocyanate; miR-214, microRNA-214; blank, cells untransfected with miR-214.
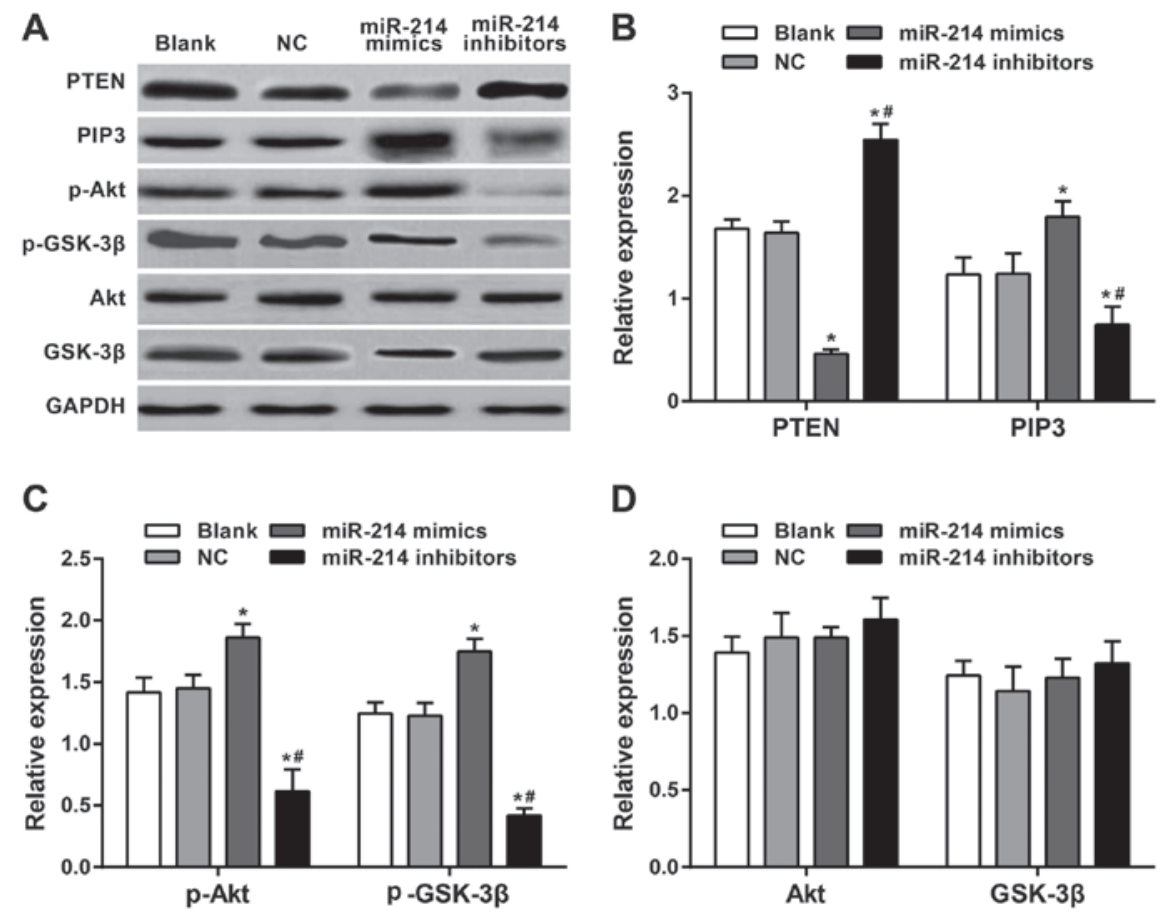

Figure 6. Western blotting of PTEN and PI3K/Akt pathway-associated proteins. (A) Expression levels were analyzed by western blotting following 48-h of

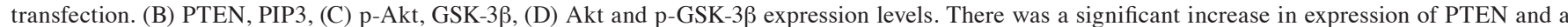
significant decrease in expression of $\mathrm{PIP}_{3}, \mathrm{p}$-Akt and p-GSK-3 $\beta$ in SK-OV-3 cells transfected with a miR-214 inhibitor compared with the blank, NC and miR-214 inhibitors groups. There was a significantly downregulated PTEN expression and significantly upregulated PIP ${ }_{3}, \mathrm{p}$-Akt and p-GSK-3 $\beta$ expression in miR-214 mimic-transfected cells compared with the blank, NC and miR-214 mimics groups. There were significant differences in PTEN, PIP ${ }_{3}$, p-Akt and p-GSK- $3 \beta$ expression between the miR-214 inhibitor group and the miR-214 mimic group. ${ }^{~} \mathrm{P}<0.05$ compared with the blank and $\mathrm{NC}$ groups; ${ }^{*} \mathrm{P}<0.05$ compared with miR-214 mimic group; sphatidylinositol $(3,4,5)$-trisphosphate; GSK, glycogen synthase kinase; p, phosphorylated; PTEN, phosphatase and tensin homolog deleted on chromosome 10; PI3K, phosphoinositide 3-kinase; Akt, protein kinase B; PIP3, phosphatidylinositol $(3,4,5)$-trisphosphate. 
Table I. Differences in the positive expression rate of PTEN protein in ovarian cancer and adjacent normal tissues.

\begin{tabular}{|c|c|c|c|c|c|}
\hline \multirow[b]{2}{*}{ Type of tissue } & \multirow[b]{2}{*}{ Number of cases } & \multicolumn{2}{|c|}{ PTEN expression, $\mathrm{n}$} & \multirow[b]{2}{*}{ PTEN positive rate, $\%$} & \multirow[b]{2}{*}{ P-value } \\
\hline & & Positive & Negative & & \\
\hline Ovarian cancer & 124 & 59 & 65 & 47.6 & $<0.001$ \\
\hline Normal tissues & 124 & 96 & 28 & 77.4 & \\
\hline
\end{tabular}

PTEN, phosphatase and tensin homolog deleted on chromosome 10; $\mathrm{P}<0.001$, compared with the ovarian cancer tissues and the adjacent tissues.

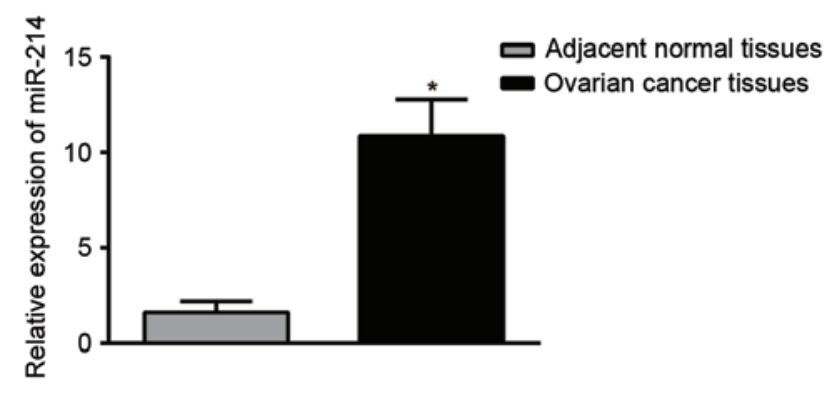

Figure 7. Expression of miR-214 in ovarian cancer tissues and adjacent normal tissues. miR-214 expression was significantly increased in the ovarian cancer tissues compared with normal tissues. ${ }^{*} \mathrm{P}<0.05$, compared with adjacent normal tissues; miR-214, microRNA-214; blank, cells untransfected with miR-214.

significantly increased compared with the other three groups (all $\mathrm{P}<0.05)$. However, the apoptotic rate was not statistically significant between the blank group and the NC group (P>0.05; Fig. 5).

Expression of PTEN and PI3K/Akt pathway-associated proteins. Western blot analysis results revealed significantly increased expression of PTEN and decreased expression of PIP3, p-Akt and p-GSK-3 $\beta$ in SK-OV-3 cells transfected with a miR-214 inhibitor (48 h later) compared with the blank group and the NC group (all $\mathrm{P}<0.05$ ). SK-OV-3 cells transfected with the miR-214 mimic exhibited significantly downregulated PTEN expression and significantly upregulated PIP3, p-Akt and $\mathrm{p}-\mathrm{GSK}-3 \beta$ expression compared with the blank and the $\mathrm{NC}$ group (all $\mathrm{P}<0.05$ ). Significant differences in PTEN, PIP3 p-Akt and p-GSK-3 $\beta$ expression levels were observed between the miR-214 inhibitor group and the miR-214 mimic group (all $\mathrm{P}<0.05)$. There were no significant differences in Akt and GSK-3 $\beta$ among all groups (all $\mathrm{P}>0.05$ ). The expression of each protein in the blank group did not significantly differ from those in the NC group (all P>0.05; Fig. 6).

Expression of miR-214 and PTEN in OC tissues and adjacent normal tissues. The results from RT-qPCR showed that OC tissues had a significantly increased expression of miR-214 in comparison with adjacent normal tissues $(\mathrm{P}<0.01$; Fig. 7$)$. Immunohistochemistry results showed that the expression of PTEN was mainly observed in the cell nucleus, and partially in the cytoplasm, and presented with yellow or brownish-yellow granules (Fig. 8). As shown in Table I, adjacent normal tissues exhibited a significantly increased rate of positive PTEN

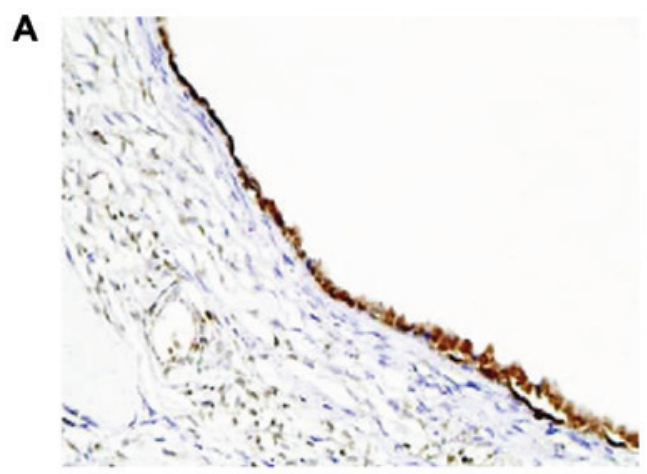

B

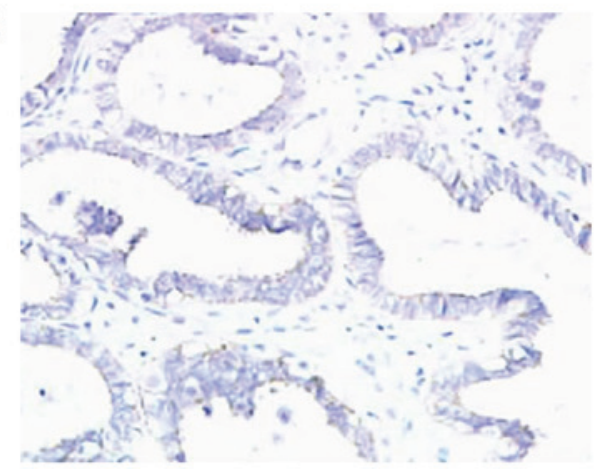

Figure 8. Expression of PTEN in ovarian cancer tissues and adjacent normal tissues PTEN. (A) Strong positive expression of PTEN in normal ovarian tissues. (B) Weak positive expression of PTEN in ovarian cancer tissues. Magnification, x200; PTEN, phosphatase and tensin homolog.

protein expression compared with OC tissues [77.4 (96/124) vs. $47.6 \%$ (59/124); $\mathrm{P}<0.05]$.

\section{Discussion}

The functional role of miR-214 in regulating PTEN-mediated PI3K/Akt signaling pathway was evaluated. It has been predicted that miR-214, which is located inside the sequence of long noncoding Dmn3os transcript, targets two activating protein 2 transcription factors, causing downstream effects on genes regulating vital cell cycle processes, including apoptosis, proliferation and angiogenesis (11). Additionally, miR-214 with pleiotropic and tumor-specific functions may contribute to the formation and progression of OC through its target genes and primary signaling networks, including PTEN/Akt, $\beta$-catenin, as well as tyrosine kinase receptor (23). The involvement of the PI3K/Akt signaling pathway in regulating cell survival, cell cycle progression and cellular growth 
has been revealed. Components of the PI3K/Akt signaling pathway are frequently altered in various types of human cancer, and the PI3K/Akt/mTOR signaling pathway has been considered as a therapeutic target for OC (24-26). In the present study, luciferase reporter gene assay indicated PTEN was as the target gene of miR-214. Important findings in the present study indicated that $\mathrm{OC}$ tissues exhibited increased expression of miR-214 and increased expression of PTEN protein compared with the adjacent normal tissues. SK-OV-3 cells transfected with miR-214 mimic exhibited significantly downregulated PTEN expression and significantly upregulated $\mathrm{PIP}_{3}, \mathrm{p}$-Akt and p-GSK- $3 \beta$ expression compared with the blank and the NC group. The cells transfected with miR-214 mimic exhibited significantly increased viability and proliferation and markedly decreased apoptotic rate. Combining these significant results, the present study supported the hypothesis that miR-214 may activate the PI3K/Akt signaling pathway by downregulating PTEN, which may promote proliferation and inhibit apoptosis of OC cells.

Extensive roles of miR-214 in promoting tumor cell proliferation, growth and invasion, as well as tumor progression and metastasis have been previously reported $(12,13,27)$. Additionally, miR-214 has been demonstrated to be implicated in the differentiation of OC stem cells into mature OC cells (28), It has been well documented that miR-214 targets PTEN and is upregulated in OC, and has oncogenic and chemoresistant functions (29). miR-214 may be useful in diagnostic tests for the early detection of OC. Transient perturbation of miR-31 and miR-214 and miR-155 expression was sufficient to convert normal ovarian fibroblasts into induced carcinoma-associated fibroblasts that promoted ovarian tumor growth and increased tumor cell invasiveness and migration $(29,30)$. Partially consistent with the role of miR-214 in downregulating PTEN and activating the PI3K/Akt signaling pathway, a previous study revealed that miR-214 induces cell survival primarily by targeting the PTEN/Akt pathway, resulting in downregulation of PTEN protein and activation of Akt pathway in human OC (15).

In conclusion, $\mathrm{OC}$ tissues exhibited increased expression of miR-214 and decreased expression of PTEN protein compared with normal tissues. miR-214 may activate the PI3K/Akt signaling pathway by downregulating the targeted PTEN, which may promote proliferation and inhibit apoptosis of OC cells and provide a potential miRNA-based targeted therapy for the treatment of OC.

\section{References}

1. Siegel R, Naishadham D and Jemal A: Cancer statistics, 2013. CA Cancer J Clin 63: 11-30, 2013.

2. Chornokur G, Amankwah EK, Schildkraut JM and Phelan CM: Global ovarian cancer health disparities. Gynecol Oncol 129 : 258-264, 2013

3. Lowe KA, Chia VM, Taylor A, O'Malley C, Kelsh M, Mohamed M, Mowat FS and Goff B: An international assessment of ovarian cancer incidence and mortality. Gynecol Oncol 130: 107-114, 2013

4. Chiang YC, Chen CA, Chiang CJ, Hsu TH, Lin MC, You SL, Cheng WF and Lai MS: Trends in incidence and survival outcome of epithelial ovarian cancer: 30-year national population-based registry in Taiwan. J Gynecol Oncol 24: 342-351, 2013.

5. Wong KH, Mang OW, Au KH and Law SC: Incidence, mortality, and survival trends of ovarian cancer in Hong Kong, 1997 to 2006 : A population-based study. Hong Kong Med J 18: 466-474, 2012.
6. Ledermann JA, Raja FA, Fotopoulou C, Gonzalez-Martin A, Colombo $\mathrm{N}$ and Sessa C; ESMO Guidelines Working Group: Newly diagnosed and relapsed epithelial ovarian carcinoma: ESMO Clinical Practice Guidelines for diagnosis, treatment and follow-up. Ann Oncol 24 (Suppl 6): vi24-vi32, 2013.

7. Katz B, Trope CG, Reich R and Davidson B: MicroRNAs in ovarian cancer. Hum Pathol 46: 1245-1256, 2015.

8. Davis-Dusenbery BN and Hata A: MicroRNA in Cancer: The involvement of aberrant microRNA biogenesis regulatory pathways. Genes Cancer 1: 1100-1114, 2010.

9. Tutar L, Tutar E and Tutar Y: MicroRNAs and cancer; an overview. Curr Pharm Biotechnol 15: 430-437, 2014.

10. Xia H, Ooi LL and Hui KM: MiR-214 targets $\beta$-catenin pathway to suppress invasion, stem-like traits and recurrence of human hepatocellular carcinoma. PLoS One 7: e44206, 2012.

11. Bar-Eli M: Searching for the 'melano-miRs': miR-214 drives melanoma metastasis. EMBO J 30: 1880-1881, 2011.

12. Penna E, Orso F, Cimino D, Tenaglia E, Lembo A, Quaglino E, Poliseno L, Haimovic A, Osella-Abate S, De Pittà C, et al: microRNA-214 contributes to melanoma tumour progression through suppression of TFAP2C. EMBO J 30: 1990-2007, 2011.

13. Xu Z and Wang T: miR-214 promotes the proliferation and invasion of osteosarcoma cells through direct suppression of LZTS1. Biochem Biophys Res Commun 449: 190-195, 2014.

14. Yang Z, Chen S, Luan X, Li Y, Liu M, Li X, Liu T and Tang H: MicroRNA-214 is aberrantly expressed in cervical cancers and inhibits the growth of HeLa cells. IUBMB Life 61: 1075-1082, 2009.

15. Yang H, Kong W, He L, Zhao JJ, O'Donnell JD, Wang J, Wenham RM, Coppola D, Kruk PA, Nicosia SV and Cheng JQ: MicroRNA expression profiling in human ovarian cancer: miR-214 induces cell survival and cisplatin resistance by targeting PTEN. Cancer Res 68: 425-433, 2008.

16. Gadducci A, Sergiampietri C, Lanfredini N and Guiggi I: Micro-RNAs and ovarian cancer: The state of art and perspectives of clinical research. Gynecol Endocrinol 30: 266-271, 2014.

17. Mabuchi S, Kuroda H, Takahashi R and Sasano T: The $\mathrm{PI} 3 \mathrm{~K} / \mathrm{AKT} / \mathrm{mTOR}$ pathway as a therapeutic target in ovarian cancer. Gynecol Oncol 137: 173-179, 2015.

18. Bai H, Li H, Li W, Gui T, Yang J, Cao D and Shen K: The $\mathrm{PI} 3 \mathrm{~K} / \mathrm{AKT} / \mathrm{mTOR}$ pathway is a potential predictor of distinct invasive and migratory capacities in human ovarian cancer cell lines. Oncotarget 6: 25520-25532, 2015.

19. Yang X, Cheng Y, Li P, Tao J, Deng X, Zhang X, Gu M, Lu Q and Yin C: A lentiviral sponge for miRNA-21 diminishes aerobic glycolysis in bladder cancer T24 cells via the PTEN/PI3K/AKT/mTOR axis. Tumour Biol 36: 383-391, 2015.

20. FIGO Oncology Committee: FIGO staging for gestational trophoblastic neoplasia 2000. FIGO Oncology Committee. Int J Gynaecol Obstet 77: 285-287, 2002.

21. Scully RE and Sobin LH: Histological Typing of Ovarian Tumours. 2nd Edition. Springer Verlag, New York, NY. 1999.

22. Livak KJ and Schmittgen TD: Analysis of relative gene expression data using real-time quantitative PCR and the 2(-Delta Delta C(T)) method. Methods 25: 402-408, 2001.

23. Penna E, Orso F and Taverna D: miR-214 as a key hub that controls cancer networks: Small player, multiple functions. J Invest Dermatol 135: 960-969, 2015.

24. Fresno Vara JA, Casado E, de Castro J, Cejas P, Belda-Iniesta C and González-Barón M: PI3K/Akt signalling pathway and cancer. Cancer Treat Rev 30: 193-204, 2004.

25. Li H, Zeng J and Shen K: PI3K/AKT/mTOR signaling pathway as a therapeutic target for ovarian cancer. Arch Gynecol Obstet 290: 1067-1078, 2014.

26. Faes S and Dormond O: PI3K and AKT: Unfaithful partners in cancer. Int J Mol Sci 16: 21138-21152, 2015.

27. Qiang R, Wang F, Shi LY, Liu M, Chen S, Wan HY, Li YX, Li X, Gao SY, Sun BC and Tang H: Plexin-B1 is a target of miR-214 in cervical cancer and promotes the growth and invasion of HeLa cells. Int J Biochem Cell Biol 43: 632-641, 2011.

28. Yin G, Chen R, Alvero AB, Fu HH, Holmberg J, Glackin C, Rutherford T and Mor G: TWISTing stemness, inflammation and proliferation of epithelial ovarian cancer cells through MIR199A2/214. Oncogene 29: 3545-3553, 2010.

29. Zaman MS, Maher DM, Khan S, Jaggi M and Chauhan SC: Current status and implications of microRNAs in ovarian cancer diagnosis and therapy. J Ovarian Res 5: 44, 2012.

30. Chou J and Werb Z: MicroRNAs play a big role in regulating ovarian cancer-associated fibroblasts and the tumor microenvironment. Cancer Discov 2: 1078-1080, 2012. 